\title{
Enhanced degradation of Bisphenol A from high saline polycarbonate plant wastewater using wet air oxidation
}

\author{
Seyyed Abbas Mirzaee ${ }^{\mathrm{a}}$, Neamat Jaafarzadeh ${ }^{\mathrm{a}, \mathrm{b}}$, Sahand Jorfi ${ }^{\mathrm{a}, \mathrm{b}}$, Helder T. Gomes ${ }^{\mathrm{c}, \mathrm{d}}$, \\ Mehdi Ahmadi ${ }^{\mathrm{a}, \mathrm{b}, *}$ \\ a Department of Environmental Health Engineering, Ahvaz Jundishapur University of Medical Sciences, Ahvaz, Iran \\ ${ }^{b}$ Environmental Technologies Research Center, Ahvaz Jundishapur University of Medical Sciences, Ahvaz, Iran \\ c Centro de Investigação de Montanha (CIMO), Instituto Politécnico de Bragança, 5300-253 Bragança, Portugal \\ ${ }^{\mathrm{d}}$ Laboratory of Separation and Reaction Engineering - Laboratory of Catalysis and Materials (LSRE-LCM), Faculdade de Engenharia, Universidade do Porto, \\ Rua Dr. Roberto Frias, 4200-465 Porto, Portugal
}

\section{A R T I C L E I N F O}

\section{Article history:}

Received 2 August 2018

Received in revised form

14 September 2018

Accepted 17 September 2018

Available online 27 September 2018

\section{Keywords:}

Polycarbonate plant

Bisphenol A

Wet air oxidation

Biodegradability

High saline wastewater

Petrochemical wastewater

\begin{abstract}
A B S T R A C T
In the present study, wet air oxidation (WAO) was investigated for the decomposition of bisphenol A(BPA) in high saline polycarbonate plant wastewater (PCW). The main operating conditions of the WAO process that affects the degradation efficiency, including temperature, total air pressure and reaction time were studied. The results indicate that complete BPA degradation is achieved in $\mathrm{pH} 8.5$, temperature $=150^{\circ} \mathrm{C}$, total air pressure of $3 \mathrm{MPa}$ and $120 \mathrm{~min}$. In addition, by prolonging the reaction time to $24 \mathrm{~h}$, removals of $62 \%$ and $37 \%$, were obtained regarding chemical oxygen demand (COD) and total oxygen carbon (TOC), respectively. The intermediates of BPA degradation generated in aqueous solution by the WAO process were identified and the proposed plausible mechanism was reported. Under optimum experimental conditions, the biodegradability of treated PCW after WAO process was shown to significantly improve, by analysis of biodegradability index, including $\mathrm{BOD}_{5} / \mathrm{COD}$ ratio, values of average oxidation state (AOS) and carbon oxidation state (COS). The WAO process was found to be an effective method to degrade highly toxic organic matter in high saline industrial wastewater such as PCW. The results indicate that WAO, as a pretreatment technology, is an economic and eco-friendly method for the treatment of PCW. (c) 2018 Institution of Chemical Engineers. Published by Elsevier B.V. All rights reserved.
\end{abstract}

\section{Introduction}

In recent years, due to the recent developments in analytical chemistry and detection the anthropogenic organic substances in water resources, there has been increasing attention to the presence of highly toxic and recalcitrant substances in aquatic environments. A large number of these highly toxic compounds have been reported that can cause disruption of endocrine systems and defined as endocrine disruption compounds (EDCs) (Akbari et al., 2016; Erjavec et al., 2013; Umar et al., 2013; Noorimotlagh et al., 2017, 2018a,b,c). Amongst the EDCs, bisphenol A [BPA; 2, 2-bis (4-hydroxyphenyl) propane or 4, 4'-isopropylidenediphenol] is considered as a representative compound and, due to the sim-

\footnotetext{
* Corresponding author at: Department of Environmental Health Engineering, Ahvaz Jundishapur University of Medical Sciences, Ahvaz, Iran.

E-mail addresses: Mirzaee.seyyed@gmail.com (S.A. Mirzaee), n.jaafarzade@yahoo.com (N. Jaafarzadeh), sahand369@yahoo.com (S. Jorfi), htgomes@ipb.pt (H.T. Gomes), Ahmadi241@gmail.com (M. Ahmadi).
}

ilar chemical structure with estrogens, exhibits adverse effects on aquatic organisms. It is reported that BPA can induce adverse effects such as feminization phenomena in various organisms, prostate cancer, type 2 diabetes, breast cancer, oxidative stress and estrogen-dependent cancers, etc. (Erjavec et al., 2013; Umar et al., 2013; Kusvuran and Yildirim, 2013; Li et al., 2013; Rutkowska et al., 2016).

BPA is generally applied by the manufacturers as an intermediate for the production of several kinds of polymeric materials such as polycarbonate products like baby bottles, epoxy resins, polyacrylates, polyvinyl chloride (PVC) and flame retardants such as tetrabromobisphenol A, among others. (Umar et al., 2013; Kusvuran and Yildirim, 2013; Mena et al., 2017). It is estimated that the world rate of BPA production in 2015 was approximately 5.4 million tones (Mena et al., 2017). The removal efficiencies of BPA in wastewater treatment plants (WWTP) were reported to be from 37 to $94 \%$ (Liu et al., 2011). Nevertheless, it was reported that the concentration of BPA is up to $17.2 \mathrm{mg} / \mathrm{L}$ in leachates at a hazardous waste landfill site in Japan, $12 \mu \mathrm{g} / \mathrm{L}$ in wastewater effluent in the United States, and 0.07 to $1.68 \mu \mathrm{g} / \mathrm{L}$ and $0.104 \mu \mathrm{g} / \mathrm{g}$ to $0.312 \mu \mathrm{g} / \mathrm{g}$ in influ- 
ent and sludge of WWTP from Quebec (Canada), respectively (Liu et al., 2011; Yamamoto et al., 2001; Kolpin et al., 2002; Mohapatra et al., 2011). Due to its high commercial usage and its ability to migrate from baby bottles, plastics and other products to water resources, BPA can exposure to human and exert its detrimental health effects such as carcinogenesis (Akbari et al., 2016; Erjavec et al., 2013; Kusvuran and Yildirim, 2013; Athalathil et al., 2015). Recently, new regulations have been introduced on the use of BPA in varnishes and coatings intended to come into contact with food and amending Regulation (EU) No 10/2011 as regards the use of that substance in plastic food contact materials (Commission Regulation (EU) $2018 / 213$ of 12 February 2018) (EC, 2018).

The main contamination pathways of BPA in the water resources are discharge of industrial and domestic wastewaters, landfill leachates and so on (Akbari et al., 2016; Vogel, 2009; Kang et al., 2007; Alavi et al., 2017). Polycarbonate (PC) plants produce a group of thermoplastic polymers containing carbonate groups in their chemical structures. PCs are produced by the reaction of BPA and phosgene $\left(\mathrm{COCl}_{2}\right)$. Polycarbonate plant wastewaters (PCW) are a complex matrix which not only contain high levels of toxic recalcitrant organic compounds such as phenol, BPA, aromatic and aliphatic hydrocarbons, but also have considerable amounts of various kinds of inorganic dissolved salts, high salinity and inorganic chemicals (Ahmadi et al., 2017a; El-Naas et al., 2010; Madadi et al., 2016; Jorfi et al., 2017; Ahmadi et al., 2017b; Esmaeli et al., 2011). PCW are also characterized by high levels of persistent organic pollutants (POPs), salinity, toxicity and low biodegradability potential for micro-organisms (Umar et al., 2013; Kusvuran and Yildirim, 2013; Ahmadi et al., 2017a,b; Ahmadi et al., 2016). Therefore, in recent years, there are growing attempts to develop efficient degradation methods for the destruction of BPA in the contaminated waters and/or wastewaters.

Conventional biological degradation processes are not efficient for these recalcitrant organic substances, such as BPA in the PCW, due to the required long residence time as well as toxicity of these organic compounds for activated sludge and micro-organisms (Erjavec et al., 2013; Ahmadi et al., 2017c; Arena et al., 2015; Ahmadimoghaddam et al., 2010). In contrast, advanced oxidation processes (AOPs) have recently been proved to be highly efficient to degrade recalcitrant organic substances based on the capability to form of highly active reactive oxidizing free radicals such as hydroxyl $(\mathrm{HO})$ and sulfate $\left(\mathrm{SO}_{4}{ }^{-}\right)$radical species (Athalathil et al., 2015; Ahmadi et al., 2016; Garoma and Matsumoto, 2009; Moussavi et al., 2018; Reddy and Kim, 2015). Several types of AOPs have been applied for the decomposition of BPA, including Vacuum-Ultraviolet (VUV) $/ \mathrm{H}_{2} \mathrm{O}_{2}$ process (Moussavi et al., 2018), electrogenerated ferrous ion activated ozone, $\mathrm{H}_{2} \mathrm{O}_{2}$ and persulfate system (Akbari et al., 2016), photochemical degradation process (Doong and Liao, 2017; Yuelai et al., 2017), Fenton and Fenton like process (Ahmadi et al., 2016; Yang et al., 2016; Park et al., 2017) and catalytic wet air oxidation process (Erjavec et al., 2013; Zhou et al., 2018). Among AOPs, wet air oxidation (WAO) is considered as one of the most important and promising techniques for the degradation of hazardous organic compounds. Additionally, WAO is a clean, one of the most economic, technologically viable and environmental-friendly method which degrade the organic contaminants or oxidizable inorganic components into biodegradable intermediates or mineralize them to $\mathrm{CO}_{2}, \mathrm{H}_{2} \mathrm{O}$ and innocuous end products under high temperatures $\left(125-320^{\circ} \mathrm{C}\right)$ and pressures (0.5-20 MPa) using a gaseous source of oxygen (either air or pure oxygen) as the oxidant (Arena et al., 2015; Kim and Ihm, 2011). Due to the exothermic nature of the reactions undergoing in WAO processes, the process is not energetically very demanding. Therefore, application of this type of destructive process for degradation of highly toxic streams such as PCW is applicable and very important. On the other hands, there is no need to add chemicals, leading to
Table 1

Characteristics of high saline polycarbonate plant wastewater (PCW).

\begin{tabular}{llll}
\hline \multirow{2}{*}{ Parameter } & Unit & Value & \\
\cline { 3 - 4 } & & Range & Average \\
\hline $\mathrm{pH}$ & Sorensen scale & $7.8-9.4$ & 8.5 \\
$\mathrm{BPA}$ (bisphenol A) & $\mathrm{mg} / \mathrm{L}$ & $44-55$ & 50 \\
$\mathrm{COD}$ (chemical oxygen demand) & $\mathrm{mg} / \mathrm{L}$ & $1580-2200$ & 1850 \\
BOD $_{5}$ (biochemical oxygen demand) & $\mathrm{mg} / \mathrm{L}$ & $175-250$ & 200 \\
BOD $/$ COD & - & $0.09-0.11$ & 0.10 \\
EC (electrical conductivity) & $\mathrm{mS} / \mathrm{cm}$ & $39-42$ & 40 \\
TOC (Total organic carbon) & $\mathrm{mg} / \mathrm{L}$ & $780-925$ & 842 \\
TSS (total suspended solids) & $\mathrm{mg} / \mathrm{L}$ & $56-70$ & 63 \\
TDS (total dissolved solids) & $\mathrm{mg} / \mathrm{L}$ & $19125-42780$ & 23820 \\
Turbidity & $\mathrm{NTU}$ & $18-30$ & 20 \\
Appearance & - & - & Yellow \\
\hline
\end{tabular}

cost reductions on the purchases of toxic chemicals. WAO involves liquid phase oxidation and its efficiency depends on temperature, oxygen partial pressure, reaction time and extent of the oxidizability of the intended contaminants (Athalathil et al., 2015; Arena et al., 2015; Zhou et al., 2018; Kim and Ihm, 2011; Tembhekar et al., 2015; Padoley et al., 2012a). Therefore, optimization of this process to degrade recalcitrant and toxic organic materials such as BPA is of utmost importance.

Most of the reported studies to remove BPA was performed in synthetic aqueous solutions, and could not be representative of real conditions, since various recalcitrant and toxic organic substances are present in real wastewater, especially in PCW. Therefore, the aim of the present study was to investigate the degradation of BPA found in PCW in petrochemical industry. In this study, a homemade stainless steel WAO reactor was employed. The influence of the main operating parameters, including reaction temperature and pressure, on BPA and total organic carbon (TOC) conversions was examined. The performance of the WAO reactor was also tested for chemical oxygen demand (COD) reduction. Finally, the biodegradability of PCW was also assessed by means of biochemical oxygen demand $\left(\mathrm{BOD}_{5}\right) / \mathrm{COD}$ ratio, average oxidation state (AOS) and carbon oxidation state (COS).

\section{Material and methods}

\subsection{Wastewater sampling and chemicals}

The PCW containing BPA was collected from a local PC production unit in Khuzestan province, southwest of Iran. Wastewater samples were taken from the plant operating under normal conditions. The collected PCW was transported to the laboratory immediately and then kept in a tight container in dark and cold conditions $\left(4^{\circ} \mathrm{C}\right)$ for further experiments. The characteristics of the wastewater generated in the PC unit are depicted in Table 1. The physico-chemical properties of PCW shows that it contains high levels of BPA as well as strong salinity with very low biodegradability. All chemicals used were analytical grade and used without further purification. Bisphenol $\mathrm{A}\left(\mathrm{C}_{15} \mathrm{H}_{16} \mathrm{O}_{2}\right.$, purity 99\%) and silver sulfate were purchased from Sigma-Aldrich Company. Acetonitrile $\left(\mathrm{CH}_{3} \mathrm{CN}\right.$, HPLC-grade, 99.9\%), water $\left(\mathrm{H}_{2} \mathrm{O}\right.$, HPLC-grade, 99.9\%), ammonia (HPLC-grade), mercury sulfate and potassium dichromate were purchased from Merck Company.

\subsection{WAO setup and operation}

Treatment of PCW containing BPA was studied in a hand-made stainless steel cylindrical WAO reactor (private and individual workshop) having $3 \mathrm{~L}$ gross volume capacity. The reactor was equipped with a rotary motor for stirring the reactor contents. The stirring speed was considered constant and kept at 200 rpm ensur- 
ing the good mass transfer from the gas to the liquid phase. The reactor was equipped with an inlet (left side), gas release valve (top of the reactor), pressure indicator (right side) and the feed inlet (top of the reactor). 1.5 L of PCW was introduced in the cylindrical reactor. Prior to reaction start, the reactor was properly sealed and check for any leakage. The reactor was equipped with a rupture disc as well as with a one-way controlled valve at the gas inlet. A programmable logic controller (PLC) was used for reactor control including desired temperature and pressure. The ceramic heating element was applied to heat the reaction mixture to a desired temperature and air was sparged into the reactor to the pre-defined level. The oxygen source in these experiments was air due to safety reasons.

\subsection{Experimental procedure}

The original PCW pH (8.5) was considered as the initial $\mathrm{pH}$ and no $\mathrm{pH}$ adjustments were done during the WAO process. Before starting batch experiments, the PCW $(1.5 \mathrm{~L})$ was poured into the reactor and heated to the pre-defined level, then air was sparged into the reactor and that moment being considered as $t_{0}=0 \mathrm{~min}$. The WAO process was performed at different operating conditions, including temperature range of $50-200^{\circ} \mathrm{C}$, total air pressure of 2 and $3 \mathrm{MPa}$ and $30-120 \mathrm{~min}$ of reaction time. The agitation speed was kept at $200 \mathrm{rpm}$. After each batch experiment, the WAO reactor was placed in a cooling condition. In the different time interval, PCW samples were taken and analyzed for $\mathrm{pH}, \mathrm{BPA}, \mathrm{COD}, \mathrm{BOD}, \mathrm{TOC}$ and biodegradability index $\left(\mathrm{BOD}_{5} / \mathrm{COD}\right.$ ratio), AOS and COS. In the next step, after optimizing the values of temperature and pressure in terms of BPA degradation were obtained, WAO process was carried out at prolonged reaction time considering a reaction time of $24 \mathrm{~h}$. Then, the results were analyzed considering the aforementioned parameters.

\subsection{Analytical procedures}

The $\mathrm{pH}$ measurements in the PCW were performed using $\mathrm{pH}$ meter (Eutech 2700). TDS and TSS (gravimetric method), COD (colorimetric method, 5220-D) were analyzed based on standard methods (American Public Health Association, APHA) (APHA, 2018). A manometric method was applied to determine 5-day biochemical oxygen demand (BOD5) by a BOD Trak (Hach). Electrical conductivity (EC) was measured by EC meter (Hach-Company). The mineralization of organic substances in wastewater was measured by a TOC analyzer (Shimadzu, Japan).

Working standard solutions of BPA were prepared by dissolving given amounts of BPA in distilled water and used for calibration of high-performance liquid chromatography (HPLC). At selected time intervals, wastewater samples were taken and then filtered using $0.22 \mathrm{~mm}$ syringe filters at least in duplicate. The concentration of BPA in the reaction samples were analyzed by a HPLC (KNAUER, Germany) equipped with 2500 ultraviolet (UV) wavelength detector. The UV detection wavelength for BPA was $214 \mathrm{~nm}$ and a C18 (100-5) column $(4.6 \mathrm{~mm} \times 250 \mathrm{~mm}$, with $5 \mu \mathrm{m}$ particle size) was used as stationary phase and was maintained at $35^{\circ} \mathrm{C}$ in the oven. The isocratic mobile phase was a mixture of $50 \%$ Millipore water and $50 \%$ acetonitrile at the flow rate of $1 \mathrm{~mL} / \mathrm{min}$ and the injection sample was $100 \mu \mathrm{L}$ (manual injection). Under these condition, retention time for BPA was $7.8 \mathrm{~min}-8.5 \mathrm{~min}$. The calibration curve at ten levels of BPA was performed (0.01-50.0 mg/L) and the obtained R-squared for the calibration curve of BPA was 0.99 . The limit of detection was $0.01 \mathrm{mg} / \mathrm{L}$ and the limit of quantification was $0.1 \mathrm{mg} / \mathrm{L}$.

The intermediates of BPA degradation in the aqueous solutions as well as in PCW were identified by liquid chromatography-mass spectrometry analysis (Shimadzu LCMS 2010 A) using a Micro-mass
Quattro Micro API mass spectrometer. Chromatogram separation was obtained on a C18 column $(100 \mathrm{~mm} \times 2.1 \mathrm{~mm}, 3 \mu \mathrm{m}$; Eclipse Atlantis T3) at ambient temperature. The MS analysis was performed in negative mode with electrospray source ionization (ESI ion source), using an interface voltage of $4 \mathrm{kV}$. The mobile phase consisted of Solvent A (70\% Acetonitrile) and solvent B (30\% $\mathrm{H}_{2} \mathrm{O}+$ $0.2 \% \mathrm{NH}_{3}$ ) with the flow rate of $0.3 \mathrm{~mL} / \mathrm{min}$. The injection volume of samples was $25 \mu \mathrm{L}$.

Finally, the biodegradability index (BI) of the treated wastewater, which defines a measure of the extent of amenability of biological degradation of wastewater, was calculated by $\mathrm{BOD}_{5} / \mathrm{COD}$ ratio, AOS and COS (Tembhekar et al., 2015; Al-Momani et al., 2002). In the present study, the analytical measurements were performed at least in duplicate and the standard deviation of the results of experimental parameters was not more than $5 \%$.

\section{Results and discussion}

\subsection{The effect of operating conditions of WAO process on BPA degradation}

\subsubsection{Influence of the reaction temperature}

The reaction temperature plays a very important role in the WAO process for degradation of aqueous organic compounds. It is reported that in the WAO system, both the reaction rate and the overall reduction of COD and/or TOC are depending on reaction temperature (Erjavec et al., 2013; Zhou et al., 2018; Pintar et al., 2008). Additionally, due to generation of the different types of free radicals at higher temperature, the mechanism of degradation of organic substances in the WAO system is strongly related to the reaction temperature (Zhou et al., 2018; Pintar et al., 2008). Fig. 1a-c shows the influence of temperature ranging from 50 to $200^{\circ} \mathrm{C}$ on BPA degradation during the WAO process. The finding demonstrated that the BPA degradation rate significantly increased at higher temperature (Fig. 1a). The chemical reaction of WAO is considered to take place via free radical mechanism. During the WAO, several types of free radical such as $\mathrm{O}^{\circ}, \mathrm{HO}^{\circ}$, and $\mathrm{HO}_{2}{ }^{\circ}$ are formed in the reaction system and were involved in a chain reaction that is divided into three phases including initiation, propagation and termination of free radicals. Co-oxidation is the dominant mechanism in the WAO process which involves the oxidation of organic molecules by free radical intermediates formed from another organic compound (Kim and Ihm, 2011; Jing et al., 2016; Luan et al., 2017). As depicted in Fig. 1a, when the reaction temperature increases from 50 to $200^{\circ} \mathrm{C}$, the degradation of BPA ranged from 20 to $100 \%$ after $120 \mathrm{~min}$. In our experiments, approximately complete removal of BPA was obtained at reaction temperatures higher than $150^{\circ} \mathrm{C}$ for $120 \mathrm{~min}$ of reaction time. Other studies are also reported similar results, which have been shown that higher operating temperatures in the catalytic WAO (CWAO) process resulted in higher organic matter removal such as biomethanated distillery wastewater, formic acid, acetic acid and phenol, o-cresol or 2-chlorophenol (Pintar et al., 2008; Padoley et al., 2012b; Suárez-Ojeda et al., 2008; Žerjav et al., 2018).

The rate of BPA degradation by WAO process was fitted to the first order kinetic based on Eq. 1.

$\operatorname{Ln} \frac{[C]}{[C] 0}=-k t$

Where $\mathrm{C}_{0}$ and $\mathrm{C}$ are the BPA concentration $(\mathrm{mg} / \mathrm{L})$ at times zero and $\mathrm{t}$, respectively. The rate constant $(\mathrm{k})$ and $\mathrm{t}$ are the first-order constant $\left(\mathrm{min}^{-1}\right)$ and reaction time $(\mathrm{min})$, respectively. The rate constant $(\mathrm{k})$ was obtained by plotting $\operatorname{Ln}\left(\mathrm{C} / \mathrm{C}_{0}\right)$ vs $\mathrm{t}$.

The half-life time reaction $\left(t_{1 / 2}\right)$ calculation is the suitable parameter to assess the rate of first-order kinetic. $t_{1 / 2}$ can be calcu- 

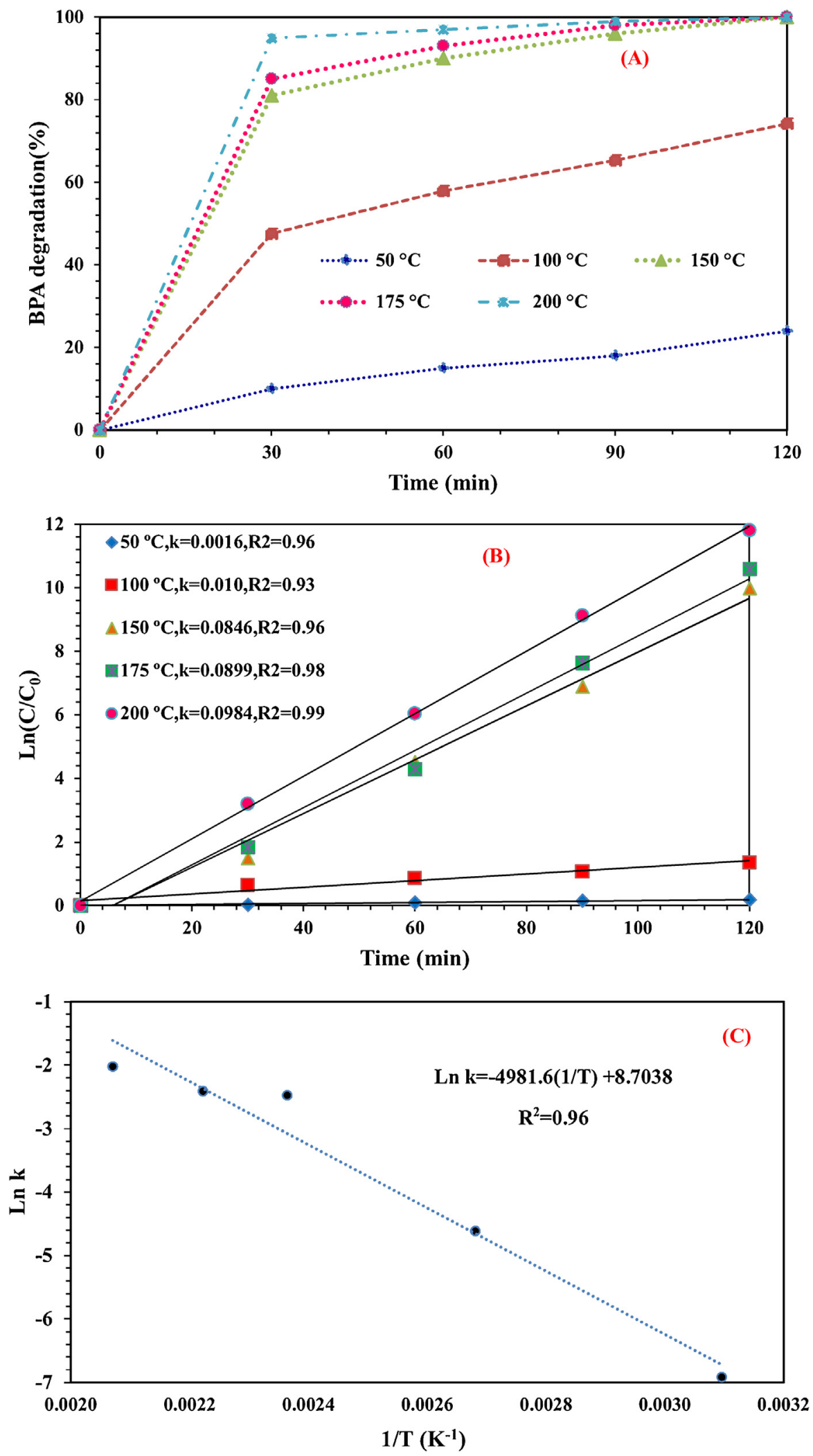

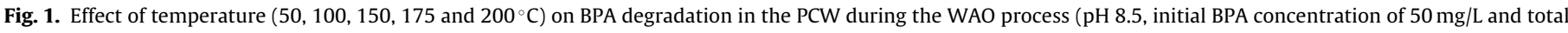
air pressure of $3 \mathrm{MPa}$ ). (a) Removal of BPA, (b) kinetics of BPA degradation, and (c) Arrhenius plot.

lated based on Eq. 2, which was derived from Eq. (1) by replacing $\mathrm{C}=0.5 \mathrm{C}_{0}$.

$\mathrm{t}_{1 / 2} \frac{\operatorname{Ln} 2}{k}=\frac{0.6931}{k}$
The rate of BPA degradation was calculated by means of the kinetic parameters $k$ and $t_{1 / 2}$. As can be seen in Fig. $1 b$, the rate constant (k) increased from $0.0016 \mathrm{~min}^{-1}$ to $0.0984 \mathrm{~min}^{-1}$ when reaction temperature was increased from 50 to $200^{\circ} \mathrm{C}$. There- 


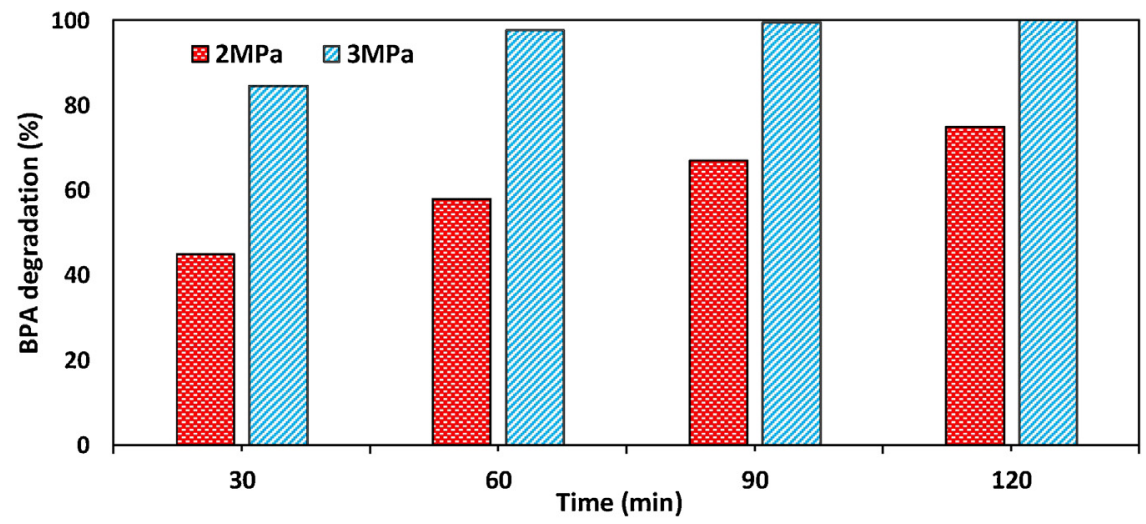

Fig. 2. Degradation of BPA in PCW by WAO process under different air pressures ( $\mathrm{pH} 8.5$, temperature $150^{\circ} \mathrm{C}$, initial $\mathrm{BPA}$ concentration $50 \mathrm{mg} / \mathrm{L}$.).

fore, the first order model was well fitted with good R-squared. These findings show that the experiment temperatures (range from $150^{\circ} \mathrm{C}-200^{\circ} \mathrm{C}$ ) had strong effects on BPA degradation. On the other hand, results demonstrated that $\mathrm{t}_{1 / 2}$ values had a decreasing trend with increasing temperature from 50 to $200^{\circ} \mathrm{C}$.

According to Fig. 1c, in order to explain the effects of temperature on the reaction rates, the activation energy for BPA degradation during the WAO process, based on the apparent kinetic rate constant at various temperatures was calculated by the Arrhenius plot using equation Eq. 3 (Noorimotlagh et al., 2018a,b; Li et al., 2015; Ribeiro et al., 2016):

$\ln k=\ln A_{0}-\frac{E_{a}}{R T}$

Where $E_{a}$ is the apparent Arrhenius activation energy ( $\left.\mathrm{kJ} / \mathrm{mol}\right), \mathrm{T}$, $A_{0}$, and $R$ are the reaction temperature $(K)$, the Arrhenius factor (also known as frequency or pre-exponential factor) $\left(\mathrm{sec}^{-1}\right)$ and the universal gas constant $(8.314 \mathrm{~J} /(\mathrm{mol} \mathrm{K}))$, respectively. As depicted in the Arrhenius plot at Fig. 1c, the apparent activation energy $\left(E_{a}\right)$ value was obtained to be $41.42 \mathrm{~kJ} / \mathrm{mol}$, which indicated that reaction temperature had a positive effect on BPA degradation by WAO process. In a similar study, Han et al. (2015) reported that decomposition of BPA in an oxidation process (ferrate (VI)) was strongly dependent on temperature with $\mathrm{E}_{\mathrm{a}}=35.67 \mathrm{~J} / \mathrm{mol}$ (Ribeiro et al., 2016; Han et al., 2015). Due to the aromatic structure of phenolic compounds, their activation energy for WAO is reported to be high. Therefore, higher reaction temperature are needed to overcome such high activation energy barriers (Zhou et al., 2018). Based on our results and in order to reduce severe operating conditions, the optimum reaction temperature was considered to be $150{ }^{\circ} \mathrm{C}$ for decomposition of the BPA present in PCW by the WAO process and used for future experiments.

\subsubsection{The effect of total air pressure}

In WAO processes, air pressure is an important parameter for organic substances degradation. The total air pressure in the WAO process influences the reaction kinetics and the distribution of intermediates. On the other hand, higher partial oxygen pressures are needed to increase the concentration of oxygen in the reaction medium in high temperature (Zhou et al., 2018). In order to determine the influence of total air pressure on the degradation of BPA in PCW, experiments were performed under two total air pressures namely, 2 and $3 \mathrm{MPa}$. The degradation of BPA in PCW by WAO under $\mathrm{pH} 8.5$, reaction temperature $150^{\circ} \mathrm{C}$, total air pressure 2 and $3 \mathrm{MPa}$ is depicted in Fig. 2. It is observed that the efficiency of WAO system under $3 \mathrm{MPa}$ was about 25\% higher than that obtained for $2 \mathrm{MPa}$. Therefore it concluded that the efficiency of WAO in the decomposition of toxic organic matter is higher at higher air pressure. According to Henry's law, higher concentration of oxygen or partial pressure of oxygen in the gas phase resulted into higher oxygen dissolution in the aqueous solution, which promotes the formation of strong oxidation species such as $\mathrm{O}_{2}{ }^{-}-$and $\mathrm{HO}_{2}$, among others (Zhou et al., 2018; Kim and Ihm, 2011). Therefore, a total air pressure of $3 \mathrm{MPa}$ was chosen for subsequent experiments.

\subsubsection{The effect of reaction time}

In the WAO systems, reaction time is also an important operating parameter. Therefore, the effect of reaction time on BPA degradation and PCW treatment in the WAO process was investigated. In this section, the WAO process was conducted in long reaction times ( $24 \mathrm{~h}$ reaction time) under optimum conditions, including $\mathrm{pH} 8.5$, reaction temperature of $150^{\circ} \mathrm{C}$ and $3 \mathrm{MPa}$ of total air pressure and obtained results is depicted in Figs. 3 and 4. As can be seen in Fig. 3, complete degradation of BPA was achieved in 120 min of reaction time, but the other organic compounds in the PCW are still high. Therefore, with the increase of the reaction time to $24 \mathrm{~h}$, the efficiency of WAO in the treatmemt of PCW was improved and the COD and TOC removal rates reached 62\% and 37\%, respectively (Fig. 3). According to Erjavec et al. (2013), in the catalytic WAO process, increasing the reaction time to $90 \mathrm{~h}$ and the reaction temperature to $210^{\circ} \mathrm{C}$, the total BPA destruction was obtained (Erjavec et al., 2013). Other review studies have reported that in the CWAO process, the increase of the reaction time had a positive effect on the decomposition of toxic organic matter (Erjavec et al., 2013; Arena et al., 2015; Kim and Ihm, 2011; Al-Momani et al., 2002; Gunale and Mahajani, 2007). So, it can be concluded that the increase of the reaction time improved significantly the mineralization of the PCW effluent. Therefore, in further experiments, the WAO process was performed at $\mathrm{pH} 8.5$, reaction temperature of $150^{\circ} \mathrm{C}, 3 \mathrm{MPa}$ of total air pressure and a reaction time of $120 \mathrm{~min}$ (prolonging for some examination to $24 \mathrm{~h}$ ).

\subsection{The intermediates of BPA degradation generated during the WAO process}

In order to identify the generated intermediates during the oxidation process, the HPLC chromatogram and LC/MS spectra of BPA decomposition and PCW treatment are determined. The HPLC chromatograms of BPA degradation in aqueous solution and treated PCW under degradation conditions of reaction temperature of $150^{\circ} \mathrm{C}$, total air pressure of $3 \mathrm{MPa}, 50 \mathrm{mg} / \mathrm{L}$ of BPA are presented in Fig. 4. It can be observed in Fig. 4, under optimum experimental conditions, the complete BPA removal as well as significantly decrease of content of organic compounds in the PCW after WAO process was achived.

According to the results of LC-MS analysis, eight possible intermediates, including BPA $\left(\mathrm{m} / \mathrm{z}=228\right.$ ) (55 min), 1, $1^{\prime}$-(2-methylprop- 


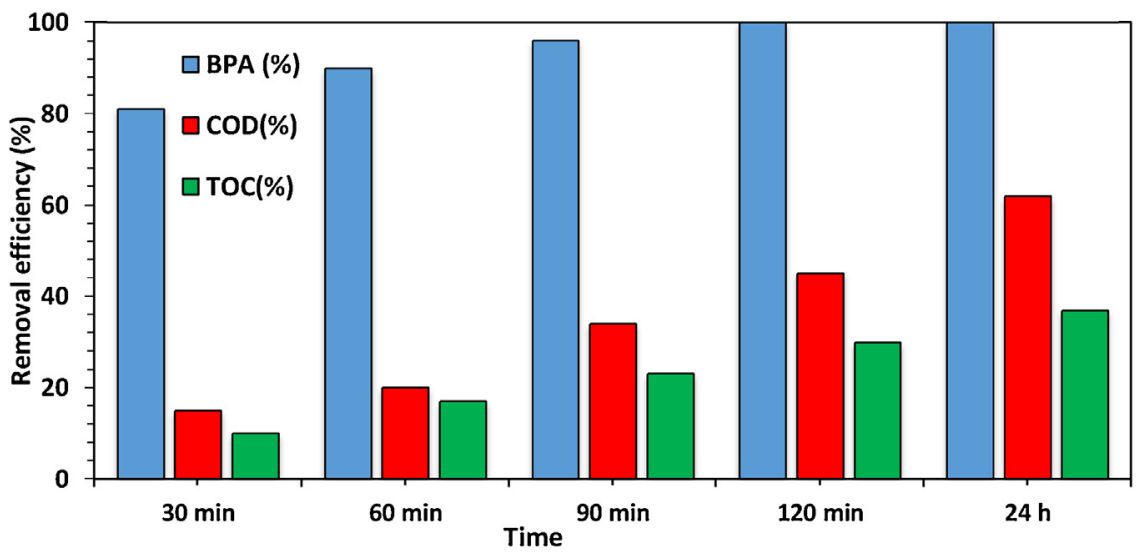

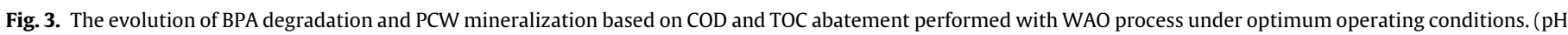
8.5 , temperature $150^{\circ} \mathrm{C}$ and total air pressure of $3 \mathrm{MPa}$, for $24 \mathrm{~h}$.).

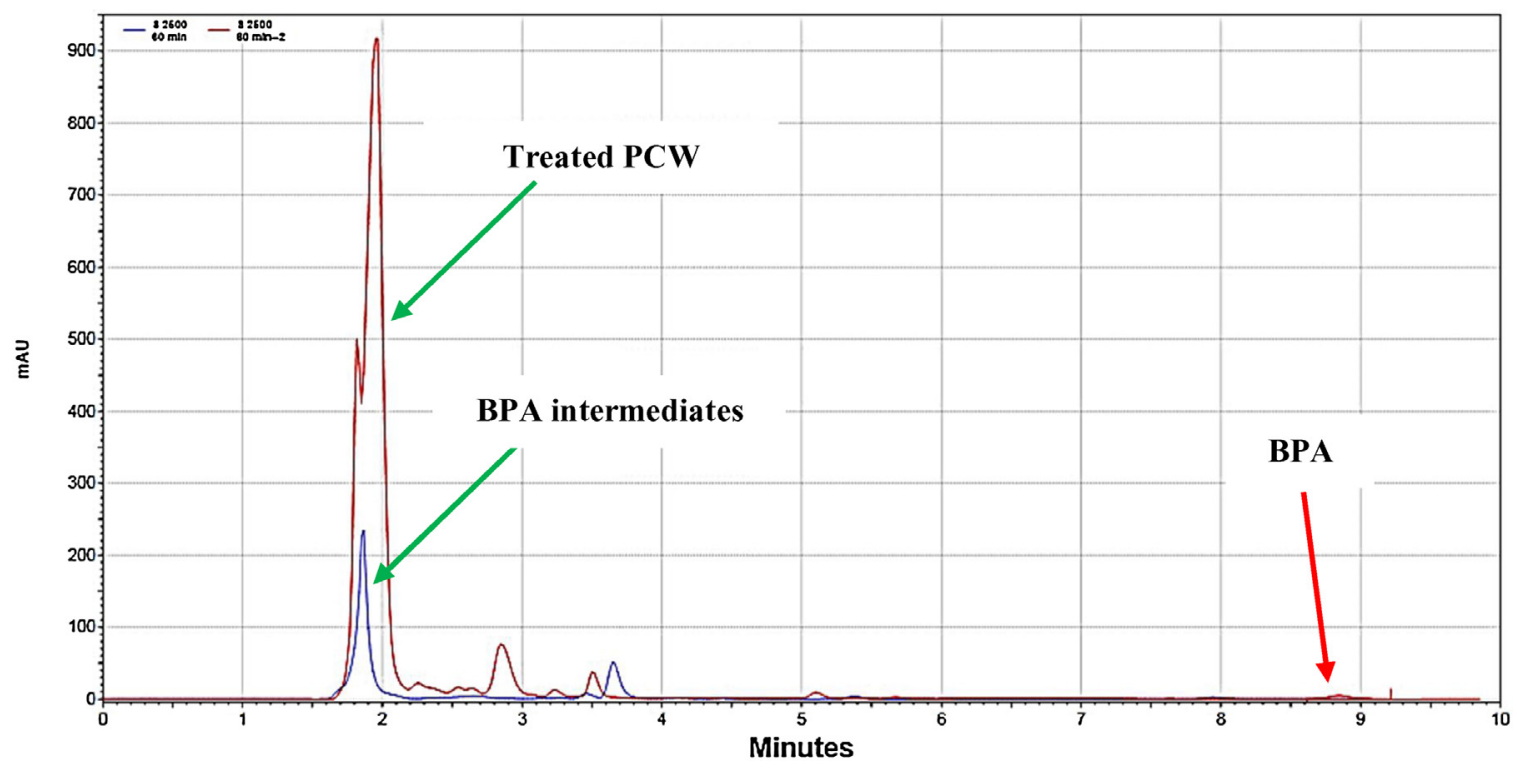

Fig. 4. Residuals of organic compounds and intermediates of BPA in aqueous solutions and treated PCW based on HPLC chromatogram.

1-ene-1,1-diyl)dibenzene $(\mathrm{m} / \mathrm{z}=208)$ (47 $\mathrm{min}), 4$-isopropylphenol $(\mathrm{m} / z=137)$ (49 $\mathrm{min})$, trihydroxybenzene $(\mathrm{m} / \mathrm{z}=128)(20 \mathrm{~min}), 1,2-$ dihydroxybenzene $(m / z=110)$ (34 $\mathrm{min})$ or 1,4-Dihydroxybenzene $(\mathrm{m} / z=110)(39 \mathrm{~min})$, Malonic acid $(\mathrm{m} / \mathrm{z}=104)(15 \mathrm{~min})$, Oxalic acid $(m / z=89.99)(10 \mathrm{~min})$ were identified during the degradation of BPA by the WAO process. Table 2 summarizes the major identified organic intermediate compounds and the corresponding open chemical structures. Based on these identified organic intermediates, a proposed reaction mechanism pathway for BPA degradation under optimum condition of WAO process was depicted in Fig. 5. It has been reported that during degradation of BPA under AOPs technique such as WAO, several mechanisms, such as $\mathrm{CO}_{2}$ elimination, dihydroxylation, $\mathrm{OH}$ group addition, cleavage of carbon-carbon bond and oxidation are involved. Considering these mechanisms, BPA degradation can be assumed to proceed by a pathway in which BPA was converted to 1,1'-(2-methylprop-1-ene-1,1diyl)dibenzene by a dehydroxylation mechanism via bonding the $\mathrm{C}-\mathrm{O}$ bonds to benzene rings, cleavage of the carbon - carbon bonds and detaching $\mathrm{OH}$ groups from BPA. In the following, 4-isopropylphenol is produced from BPA degradation through cleavage of carbon - carbon double bounds which connecting phenyl groups of BPA. With continued degradation process, further oxidation performed by reactive oxygen species led to the generation of the trihydroxybenzene, 1, 2-dihydroxybenzene or 1, 4-Dihydroxybenzene (Han et al., 2015; Takdastan et al., 2018). Thereafter, the reactive oxygen species react with these formed intermediates to generate short-chain carboxylic acids such as Malonic acid and Oxalic acid by deprotonation and opening the benzene ring processess. Short-chain carboxylic acids are stable compounds in the WAO process and other degradation technique is required to further oxidation reactions. Finally, we can conclude that the reactive oxidizing species generated in the WAO process played the key role in the degradation of BPA into smaller molecular compounds. Additionally, WAO process used as a pretreatment method, shows appropriate performance in the treatment of PCW.

\subsection{Mineralization and biodegradability studies of treated PCW}

The WAO systems and mechanism have been studied by previous researchers (Zhou et al., 2018; Kim and Ihm, 2011; Jing et al., 2016; Luan et al., 2017; Padoley et al., 2012b). Since the reaction mechanism of WAO is very complex, the definite mechanisms and reaction pathways for WAO of organic substances have not been presented even for a pure substance. Therefore, determination of mechanisms and reaction pathways of WAO is more complicated in the case of industrial wastewater due to presence of many com- 
Table 2

The major identified organic intermediate compounds.

\begin{tabular}{|c|c|c|c|c|c|}
\hline No. & by-product name & Open structure & Molecular weight (MW) & Chemical formula & Identifed $\mathrm{m} / \mathrm{z}$ \\
\hline 1 & BPA (2,2-Bis(4-hydroxyphenyl)propane) & & 228.29 & $\mathrm{C}_{15} \mathrm{H}_{16} \mathrm{O}_{2}$ & 228 \\
\hline 2 & 1,1'-(2-methylprop-1-ene-1,1-diyl)dibenzene & & 208 & $\mathrm{C}_{16} \mathrm{H}_{16}$ & 208 \\
\hline 3 & 4-isopropylphenol & & 137 & $\mathrm{C}_{9} \mathrm{H}_{12} \mathrm{O}$ & 137 \\
\hline 4 & Trihydroxybenzene & $\mathrm{OH}$ & 128 & $\mathrm{C}_{6} \mathrm{H}_{6} \mathrm{O}_{3}$ & 128 \\
\hline 5 & 1,2-dihydroxybenzene & & 110 & $\mathrm{C}_{6} \mathrm{H}_{6} \mathrm{O}_{2}$ & 110 \\
\hline 6 & 1, 4-Dihydroxybenzene & & 110 & $\mathrm{C}_{6} \mathrm{H}_{6} \mathrm{O}_{2}$ & 110 \\
\hline 7 & Malonic acid & & 104 & $\mathrm{C}_{3} \mathrm{H}_{4} \mathrm{O}_{4}$ & 104 \\
\hline 8 & Oxalic acid & Ö & 89.99 & $\mathrm{C}_{2} \mathrm{H}_{2} \mathrm{O}_{4}$ & 89.99 \\
\hline
\end{tabular}

pounds in the waste stream. The oxidation of such waste stream is much more complex than the oxidation of single/pure organic compounds in aqueous solutions.

In the present study, although complete BPA removal was obtained, complete degradation of other organic compounds in the PCW was not achieved by the WAO process after even prolonging reaction time to $24 \mathrm{~h}$ under optimum conditions $(\mathrm{pH} 8.5$, temperature $150^{\circ} \mathrm{C}$ and total air pressure of $3 \mathrm{MPa}$ ). Fig. 3 illustrates the degradation rate of BPA, COD and TOC abatement under optimum experimental conditions. As can be observed in Fig. 3, complete BPA removal was obtained under optimum conditions found for the WAO process, while COD and TOC abatement was very lower than BPA. The COD and TOC removals were still only $62 \%$ and $37 \%$, respectively (Fig. 3 ). This can be related to the fact that many intermediates were formed during the degradation of organic compounds in the PCW and many of them are persistent to decomposition in the WAO process. Taking into consideration that the WAO process may improve the biodegradability of treated PCW and reduce its toxicity, the biodegradability of treated PCW by WAO process was assessed in terms of biodegradability index including $\mathrm{BOD}_{5} / \mathrm{COD}, \mathrm{AOS}$ and $\mathrm{COS}$. The values of $\mathrm{AOS}$ and $\mathrm{COS}$ are both in the range of -4 for the methane $\left(\mathrm{CH}_{4}\right)$ as the most reduced state of carbon and +4 for the $\mathrm{CO}_{2}$ as the most oxidized state of carbon. The values of AOS and COS can be calculated based on Eqs. 4 and 5 (Noorimotlagh et al., 2018b; Ahmadi et al., 2017a; Jonidi Jafari et al., 2017):

$\mathrm{AOS}=4-1.5\left[\frac{C O D}{T O C}\right]$
$\operatorname{COS}=4-1.5\left[\frac{C O D}{T O C_{i}}\right]$

Where, COD is the COD concentration at time $\mathrm{t}\left(\mathrm{mg} \mathrm{O}_{2} / \mathrm{L}\right), \mathrm{TOC}_{\mathrm{i}}$ and TOC are the initial TOC concentration and TOC concentration at time $\mathrm{t}(\mathrm{mg} \mathrm{C} / \mathrm{L})$, respectively. Fig. 6 shows the significant enhancement of AOS and COS values for raw and treated PCW obtained by the WAO process, which reveals the considerable biodegradability improvement of treated PCW. As it can be seen in Fig. 6 and Table 1, due to the presence of recalcitrant and highly toxic organic substances in the raw $\mathrm{PCW}$, the $\mathrm{BOD}_{5} / \mathrm{COD}$ ratio of the raw PCW was 0.12 . This value indicate that raw PCW has low biodegradability, considering that $\mathrm{BOD}_{5} / \mathrm{COD}$ values are in the range from zero (indicating no biodegradability) to 1 (indicating complete biodegradability). The $\mathrm{BOD}_{5} / \mathrm{COD}$ value of $\geq 0.4$ for the wastewater is considered for biological treatment. After applying WAO process for PCW under optimum condition, the $\mathrm{BOD}_{5} / \mathrm{COD}$ ratio was enhanced to 0.41 , meaning that the treated PCW was more biodegradable. This phenomena is related to the intermediates generated during degradation of organic compounds in the WAO process. The oxidation of organic compounds in the WAO process involves several pathways and resulted in the formation of various intermediates, such as short-chain carboxylic acids, including acetic acid, formic acid, oxalic acid, etc., regardless of the initial organic substance, which are suitable substrates for biological treatment (Kim and Ihm, 2011; Jing et al., 2016). It has been proven, by indirect analysis of changing $\mathrm{pH}$ during the reaction process, that basic $\mathrm{pH}$ in raw wastewater (about 8.5 ) become slightly acidic in treated wastewater (about $6.5)$, which can only be due to the formation of short-chain car- 


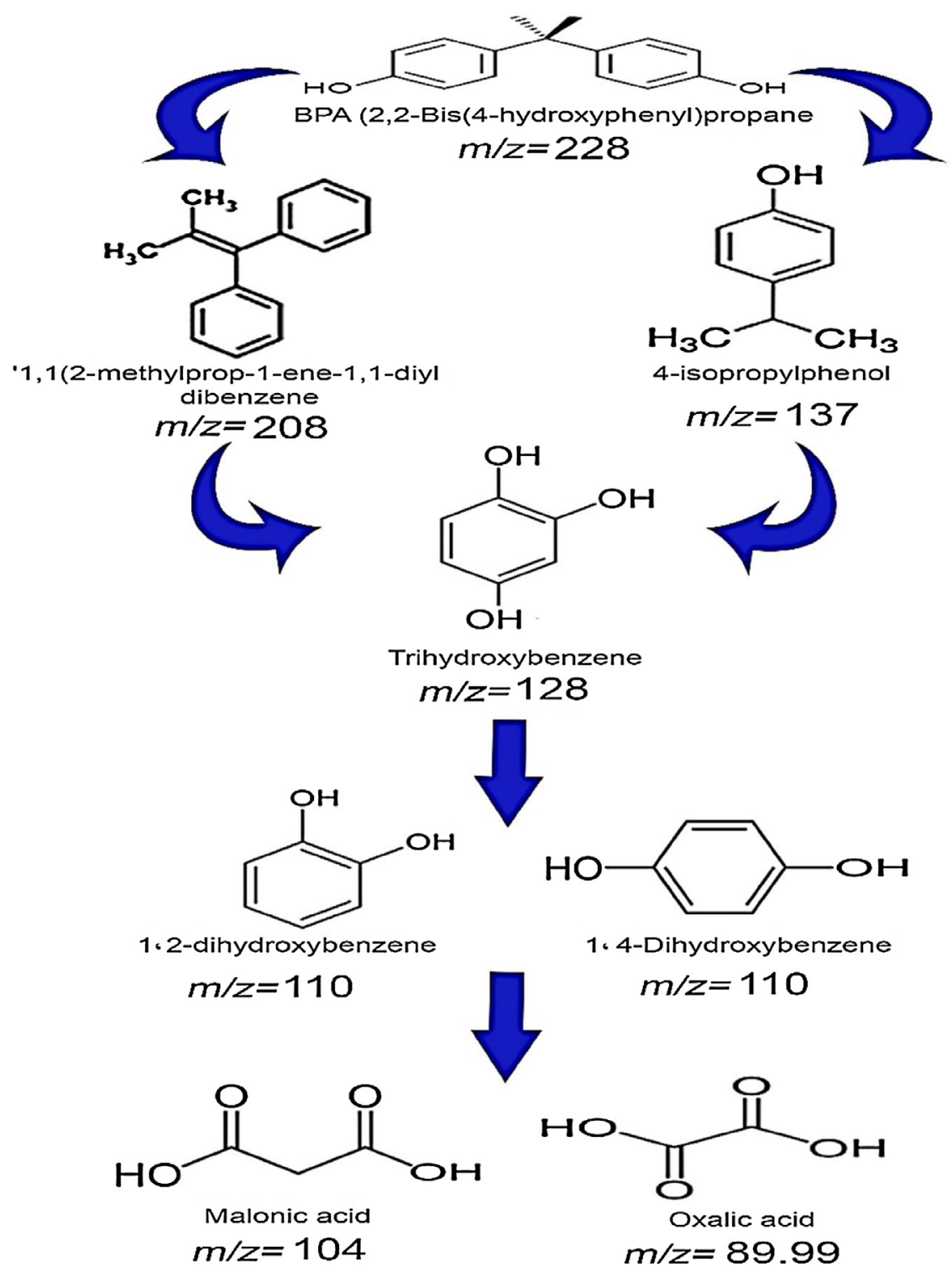

Fig. 5. Proposed pathway for BPA degradation in the WAO process system.

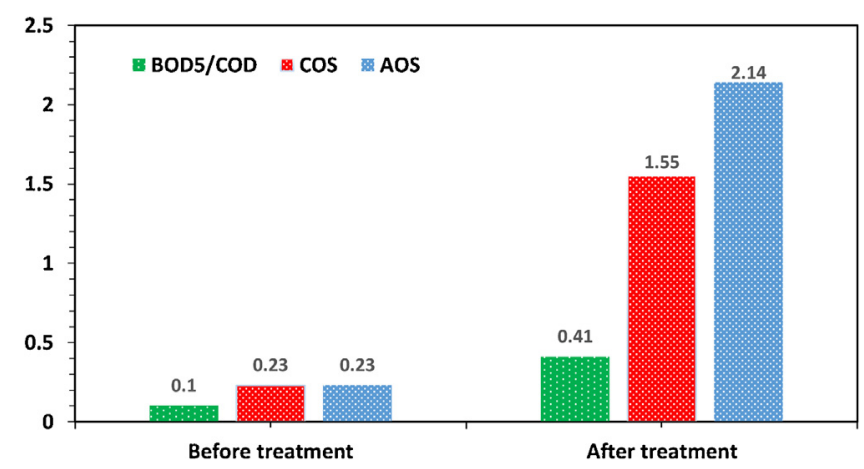

Fig. 6. The biodegradability index $\left(\mathrm{BOD}_{5} / \mathrm{COD}\right.$, $\mathrm{AOS}$, and $\left.\mathrm{COS}\right)$ for PCW obtained by WAO process under optimum condition ( $\mathrm{pH} 8.5$, temperature $150^{\circ} \mathrm{C}$ and total air pressure of $3 \mathrm{MPa}$, for $24 \mathrm{~h}$.).

boxylic acids. Other studies have also reported similar results in terms of biodegradability index improvement by WAO system for other type of wastewater (Tembhekar et al., 2015; Gunale and Mahajani, 2007; Malik et al., 2014; Weber et al., 2015; Yang et al.,
2010). In conclusion, it can be expressed that the WAO process as a pretreatment can provide suitable conditions for biodegradation of treated PCW.

\section{Conclusion}

In the present study, the efficiency of WAO system for the oxidation process of BPA in PCW was studied. Under optimum experimental conditions, complete removal of BPA was achieved in $120 \mathrm{~min}$ at $150^{\circ} \mathrm{C}, \mathrm{pH} 8.5$ and $3 \mathrm{MPa}$ of total air pressure. The reduction of COD and TOC were obtained $62 \%$ and $37 \%$, respectively. The biodegradability of treated PCW was shown to significantly improve by biodegradability index assessment including $\mathrm{BOD}_{5} / \mathrm{COD}$ ratio (increased from 0.10 to 0.41 ), as well as the values of AOS and COS. The WAO process, as a destructive technology, has proven an efficient way to degrade recalcitrant and highly toxic organic compounds in the high saline petrochemical wastewater including PCW. 


\section{Acknowledgments}

This study was a part of a funded Ph.D. thesis of Seyyed Abbas Mirzaee and was financially supported by Environmental Technologies Research Center, Ahvaz Jundishapur University of Medical Sciences (grant No. ETRC9612). The authors are also grateful to Mrs. Atashin and Mrs. Azizi for running the TOC and HPLC analyzer, respectively.

\section{References}

Ahmadi, M., Rahmani, H., Takdastan, A., Jaafarzadeh, N., Mostoufi, A., 2016. A novel catalytic process for degradation of bisphenol A from aqueous solutions: a synergistic effect of nano-Fe3O4@Alg-Fe on 03/H2O2. Process. Saf. Environ. Prot. 104, 413-421.

Ahmadi, M., Kakavandi, B., Jaafarzadeh, N., Akbar Babaei, A., 2017a. Catalytic ozonation of high saline petrochemical wastewater using PAC@FeIIFe2IIIO4: Optimization, mechanisms and biodegradability studies. Sep. Purif. Technol. 177, 293-303.

Ahmadi, M., Jorfi, S., Kujlu, R., Ghafari, S., Darvishi Cheshmeh Soltani, R., Jaafarzadeh Haghighifard, N., 2017b. A novel salt-tolerant bacterial consortium for biodegradation of saline and recalcitrant petrochemical wastewater. J. Environ. Manage. $191,198-208$.

Ahmadi, M., Kakavandi, B., Jorfi, S., Azizi, M., 2017c. Oxidative degradation of aniline and benzotriazole over PAC@FeIIFe2IIIO4: a recyclable catalyst in a heterogeneous photo-Fenton-like system. J. Photochem. Photobiol. A: Chem. 336, 42-53.

Ahmadimoghaddam, M., Mesdaghinia, A., Naddafi, K., Nasseri, S., Mahvi, A., Vaezi, F., Nabizadeh, R., 2010. Degradation of 2, 4-dinitrophenol by photo fenton process. Asian J. Chem. 22, 1009.

Akbari, S., Ghanbari, F., Moradi, M., 2016. Bisphenol A degradation in aqueous solutions by electrogenerated ferrous ion activated ozone, hydrogen peroxide and persulfate: applying low current density for oxidation mechanism. Chem. Eng. J. 294, 298-307.

Alavi, N., Salamifar, H., Mohammadi, M.J., Almasian, M., Hassani, A.H., Majlesi, M., Mirzaee, S.A., 2017. Removal of ammonium and organic carbon from leachate by the anammox process in a fixed bed bioreactor. Desalin. Water Treat. 99, 330-337.

Al-Momani, F., Touraud, E., Degorce-Dumas, J.R., Roussy, J., Thomas, O., 2002. Biodegradability enhancement of textile dyes and textile wastewater by VUV photolysis. J. Photochem. Photobiol. A: Chem. 153, 191-197.

APHA, Standard methods for the examination of water and wastewater, 20th ed., 2005.

Arena, F., Di Chio, R., Gumina, B., Spadaro, L., Trunfio, G., 2015. Recent advances on wet air oxidation catalysts for treatment of industrial wastewaters. Inorganica Chim. Acta 431, 101-109.

Athalathil, S., Erjavec, B., Kaplan, R., Stüber, F., Bengoa, C., Font, J., Fortuny, A., Pintar, A., Fabregat, A., 2015. TiO2-sludge carbon enhanced catalytic oxidative reaction in environmental wastewaters applications. J. Hazard. Mater. 300, 406-414.

Doong, R.-a., Liao, C.-Y., 2017. Enhanced visible-light-responsive photodegradation of bisphenol $\mathrm{A}$ by $\mathrm{Cu}, \mathrm{N}$-codoped titanate nanotubes prepared by microwaveassisted hydrothermal method. J. Hazard. Mater. 322, 254-262.

THE EUROPEAN COMMISSION, C.R.E. 2018/213, on the use of bisphenol A in varnishes and coatings intended to come into contact with food and amending Regulation (EU) No 10/2011 as regards the use of that substance in plastic food contact materials, in, of 12 February 2018.

El-Naas, M.H., Al-Zuhair, S., Alhaija, M.A., 2010. Removal of phenol from petroleum refinery wastewater through adsorption on date-pit activated carbon. Chem. Eng. J. 162, 997-1005.

Erjavec, B., Kaplan, R., Djinović, P., Pintar, A., 2013. Catalytic wet air oxidation of bisphenol A model solution in a trickle-bed reactor over titanate nanotubebased catalysts. Appl. Catal. B 132-133, 342-352.

Esmaeli, R., Hassani, A., Eslami, A., Ahmadi Moghadam, M., Safari, A., 2011. Di-(2ethylhexyl) phthalate oxidative degradation by fenton process in synthetic and real petrochemical wastewater. Iran. J. Environ. Health Sci. Eng. (IJEHSE) 8.

Garoma, T., Matsumoto, S., 2009. Ozonation of aqueous solution containing bisphenol A: effect of operational parameters. J. Hazard. Mater. 167, 1185-1191.

Gunale, T.L., Mahajani, V.V., 2007. Studies in mineralization of aqueous aniline using Fenton and wet oxidation (FENTWO) as a hybrid process. J. Chem. Technol. Biotechnol. 82, 108-115.

Han, Q., Wang, H., Dong, W., Liu, T., Yin, Y., Fan, H., 2015. Degradation of bisphenol A by ferrate (VI) oxidation: kinetics, products and toxicity assessment. Chem. Eng. J. 262, 34-40

Jing, G., Luan, M., Chen, T., 2016. Progress of catalytic wet air oxidation technology. Arab. J. Chem. 9, S1208-S1213.

Jonidi Jafari, A., Kakavandi, B., Jaafarzadeh, N., Rezaei Kalantary, R., Ahmadi, M., Akbar Babaei, A., 2017. Fenton-like catalytic oxidation of tetracycline by AC@Fe3O4 as a heterogeneous persulfate activator: adsorption and degradation studies. J. Ind. Eng. Chem. 45, 323-333.

Jorfi, S., Pourfadakari, S., Ahmadi, M., 2017. Electrokinetic treatment of high saline petrochemical wastewater: evaluation and scale-up. J. Environ. Manage. 204, $221-229$.
Kang, J.-H., Aasi, D., Katayama, Y., 2007. Bisphenol A in the aquatic environment and its endocrine-disruptive effects on aquatic organisms. Crit. Rev. Toxicol. 37, $607-625$.

Kim, K.-H., Ihm, S.-K., 2011. Heterogeneous catalytic wet air oxidation of refractory organic pollutants in industrial wastewaters: a review. J. Hazard. Mater. 186, 16-34.

Kolpin, D.W., Furlong, E.T., Meyer, M.T., Thurman, E.M., Zaugg, S.D., Barber, L.B. Buxton, H.T., 2002. Pharmaceuticals, hormones, and other organic wastewater contaminants in U.S. streams, 1999-2000: a national reconnaissance. Environ. Sci. Technol. 36, 1202-1211.

Kusvuran, E., Yildirim, D., 2013. Degradation of bisphenol A by ozonation and determination of degradation intermediates by gas chromatography-mass spectrometry and liquid chromatography-mass spectrometry. Chem. Eng. J.220, $6-14$.

Li, Y., Luh, C.J., Burns, K.A., Arao, Y., Jiang, Z., Teng, C.T., Tice, R.R., Korach, K.S., 2013. Endocrine-disrupting chemicals (EDCs): in vitro mechanism of estrogenic activation and differential effects on ER target genes. Environ. Health Perspect. 121, 459 .

Li, R., Jin, X., Megharaj, M., Naidu, R., Chen, Z., 2015. Heterogeneous Fenton oxidation of 2,4-dichlorophenol using iron-based nanoparticles and persulfate system. Chem. Eng. J. 264, 587-594.

Liu, W., Zhang, H., Cao, B., Lin, K., Gan, J., 2011. Oxidative removal of bisphenol A using zero valent aluminum-acid system. Water Res. 45, 1872-1878.

Luan, M., Jing, G., Piao, Y., Liu, D., Jin, L., 2017. Treatment of refractory organic pollutants in industrial wastewater by wet air oxidation. Arab. J. Chem. 10, S769-S776.

Madadi, R., Pourbabaee, A., Tabatabaei, M., Zahed, M., Naghavi, M., 2016. Treatment of petrochemical wastewater by the green algae Chlorella vulgaris. Int. J. Environ. Res. 10, 555-560.

Malik, S.N., Saratchandra, T., Tembhekar, P.D., Padoley, K.V., Mudliar, S.L., Mudliar, S.N., 2014. Wet air oxidation induced enhanced biodegradability of distillery effluent. J. Environ. Manage. 136, 132-138.

Mena, I.F., Diaz, E., Rodriguez, J.J., Mohedano, A.F., 2017. CWPO of bisphenol A with iron catalysts supported on microporous carbons from grape seeds activation. Chem. Eng. J. 318, 153-160.

Mohapatra, D.P., Brar, S.K., Tyagi, R.D., Surampalli, R.Y., 2011. Occurrence of bisphenol A in wastewater and wastewater sludge of CUQ treatment plant. J. Xenobiotics 1.

Moussavi, G., Pourakbar, M., Shekoohiyan, S., Satari, M., 2018. The photochemical decomposition and detoxification of bisphenol A in the VUV/H2O2 process: Degradation, mineralization, and cytotoxicity assessment. Chem. Eng. J. 331, $755-764$.

Noorimotlagh, Z., Haghighi, N.J., Ahmadimoghadam, M., Rahim, F., 2017. An updated systematic review on the possible effect of nonylphenol on male fertility. Environ. Sci. Pollut. Res. - Int. 24, 3298-3314.

Noorimotlagh, Z., Kazeminezhad, I., Jaafarzadeh, N., Ahmadi, M., Ramezani, Z., Silva Martinez, S., 2018a. The visible-light photodegradation of nonylphenol in the presence of carbon-doped TiO2 with rutile/anatase ratio coated on GAC: Effect of parameters and degradation mechanism. J. Hazard. Mater. 350, 108-120.

Noorimotlagh, Z., Kazeminezhad, I., Jaafarzadeh, N., Ahmadi, M., Ramezani, Z., 2018b. Nonylphenol degradation using immobilized carbon-doped TiO2 (Rutile/Anatase) under visible illumination: effect of operational parameters and degradation pathway. Chem. Eng. J.

Noorimotlagh, Z., Mirzaee, S.A., Ahmadi, M., Jaafarzadeh, N., Rahim, F., 2018c. The possible DNA damage induced by environmental organic compounds: The case of Nonylphenol. Ecotoxicol. Environ. Saf. 158, 171-181.

Padoley, K., Tembhekar, P., Saratchandra, T., Pandit, A., Pandey, R., Mudliar, S., 2012a. Wet air oxidation as a pretreatment option for selective biodegradability enhancement and biogas generation potential from complex effluent. Bioresour. Technol. 120, 157-164.

Padoley, K.V., Tembhekar, P.D., Saratchandra, T., Pandit, A.B., Pandey, R.A., Mudliar, S.N., 2012b. Wet air oxidation as a pretreatment option for selective biodegradability enhancement and biogas generation potential from complex effluent. Bioresour. Technol. 120, 157-164.

Park, C.M., Heo, J., Yoon, Y., 2017. Oxidative degradation of bisphenol A and $17 \alpha-$ ethinyl estradiol by Fenton-like activity of silver nanoparticles in aqueous solution. Chemosphere 168, 617-622.

Pintar, A., Batista, J., Tišler, T., 2008. Catalytic wet-air oxidation of aqueous solutions of formic acid, acetic acid and phenol in a continuous-flow trickle-bed reactor over Ru/TiO2 catalysts. Appl. Catal. B 84, 30-41.

Reddy, P.V.L., Kim, K.-H., 2015. A review of photochemical approaches for the treatment of a wide range of pesticides. J. Hazard. Mater. 285, 325-335.

Ribeiro, R.S., Frontistis, Z., Mantzavinos, D., Venieri, D., Antonopoulou, M., Konstantinou, I., Silva, A.M.T., Faria, J.L., Gomes, H.T., 2016. Magnetic carbon xerogels for the catalytic wet peroxide oxidation of sulfamethoxazole in environmentally relevant water matrices. Appl. Catal. B 199, 170-186.

Rutkowska, A.Z., Szybiak, A., Serkies, K., Rachon, D., 2016. Endocrine disrupting chemicals as potential risk factor for estrogen-dependent cancers. Pol. Arch. Med. Wewn. 126, 562-570.

Suárez-Ojeda, M.E., Carrera, J., Metcalfe, I.S., Font, J., 2008. Wet air oxidation (WAO) as a precursor to biological treatment of substituted phenols: refractory nature of the WAO intermediates. Chem. Eng. J. 144, 205-212.

Takdastan, A., Kakavandi, B., Azizi, M., Golshan, M., 2018. Efficient activation of peroxymonosulfate by using ferroferric oxide supported on carbon/UV/US system: a new approach into catalytic degradation of bisphenol A. Chem. Eng. J. 331, 729-743. 
Tembhekar, P.D., Padoley, K.V., Mudliar, S.L., Mudliar, S.N., 2015. Kinetics of wet air oxidation pretreatment and biodegradability enhancement of a complex industrial wastewater. J. Environ. Chem. Eng. 3, 339-348.

Umar, M., Roddick, F., Fan, L., Aziz, H.A., 2013. Application of ozone for the removal of bisphenol A from water and wastewater - a review. Chemosphere 90, 2197-2207.

Vogel, S.A., 2009. The politics of plastics: the making and unmaking of Bisphenol A "Safety". Am. J. Public Health 99, S559-S566.

Weber, B., Chavez, A., Morales-Mejia, J., Eichenauer, S., Stadlbauer, E.A., Almanza, R., 2015. Wet air oxidation of resorcinol as a model treatment for refractory organics in wastewaters from the wood processing industry. J. Environ. Manage. $161,137-143$

Yamamoto, T., Yasuhara, A., Shiraishi, H., Nakasugi, O., 2001. Bisphenol A in hazardous waste landfill leachates. Chemosphere 42, 415-418.
Yang, S., Liu, Z., Huang, X., Zhang, B., 2010. Wet air oxidation of epoxy acrylate monomer industrial wastewater. J. Hazard. Mater. 178, 786-791.

Yang, X.-j., Xu, X.-m., Xu, X.-c., Xu, J., Wang, H.-l., Semiat, R., Han, Y.-f., 2016. Modeling and kinetics study of Bisphenol A (BPA) degradation over an FeOCl/SiO2 Fentonlike catalyst. Catal. Today 276, 85-96.

Yuelai, H.F., LIU, Min W.E.I., Keluan, Y.I.N., Jianwen, Y.A.N., 2017. From edible landscape to vital communities: clover nature school community gardens in Shanghai. Landsc. Archit. Front. 5, 72-83.

Žerjav, G., Kaplan, R., Pintar, A., 2018. Catalytic wet air oxidation of bisphenol A aqueous solution in trickle-bed reactor over single TiO2 polymorphs and their mixtures. J. Environ. Chem. Eng. 6, 2148-2158.

Zhou, L., Cao, H., Descorme, C., Xie, Y., 2018. Phenolic compounds removal by wet air oxidation based processes. Front. Environ. Sci. Eng. 12, 1. 